Environmental Science and Technology

\title{
Glass transitions in peat - their relevance and the impact of water
}

Gabriele E. SChaumanN ${ }^{* \dagger}$ AND Eugene J. LeBoeuF ${ }^{\ddagger}$

University of Technology Berlin, Institute of Environmental Technology, Department of

Environmental Chemistry, KF3, Straße des 17. Juni 135, D-10623 Berlin

\section{--- Supporting Information --- Contents ---}

\section{Experimental Section}

- Scheme of sample pre-treatment (Fig. SI-1)

- Thermogravimetry (TG)

\section{Results}

- Representative DSC thermograms of the air dried peat sample (Fig. SI-2)

- Thermogravimetry results

- Weight loss (DTG) and DTA trace of thermogravimetry (Fig. SI-3)

- Water uptake from the atmosphere: water content as function of hydration time (Fig. SI-4)

- List of abbreviations (Table SI-1)

\footnotetext{
* Corresponding author phone: +49(30)314-73173; fax: +49(30)314-29319; email:

Gabi.Schaumann@TU-Berlin.DE

$\dagger$ University of Technology, Berlin, Germany

$*$ Vanderbilt University, Nashville, Tennessee, USA
} 


\section{Experimental Section}

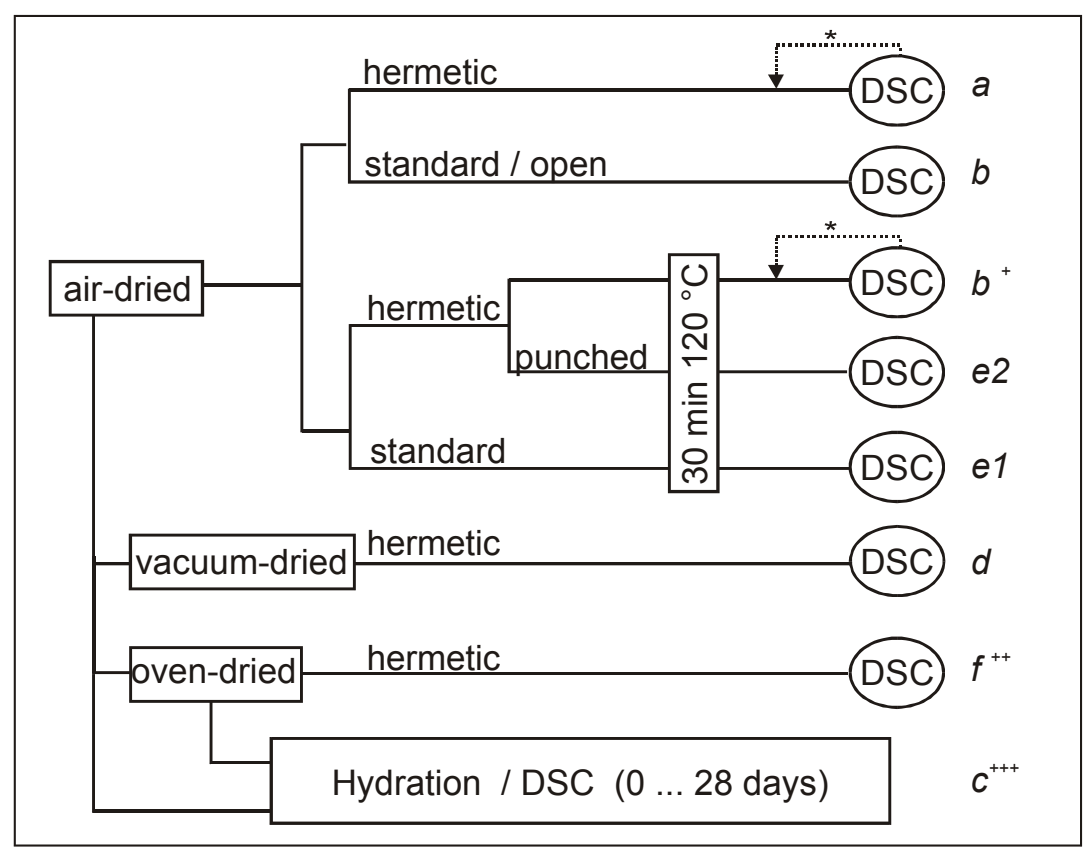

Fig. SI-1. Scheme of sample pre-treatment described in the methods section. "Hermetic" and "standard" characterize the DSC pan type; "punched" indicates that three holes were punched into the lid of the hermetic pan. The dotted line marked with " $*$ " indicates that the samples were re-investigated in their respective pans after several days of storage at $20^{\circ} \mathrm{C}$. The letters indicate the corresponding plot in Fig. 1.

$b^{+} \quad$ plot $b$ in Fig. 1 is representative of this pre-treatment

$f^{++}$plot $\mathrm{d}$ in Fig. 1 is representative of the oven-dried sample

$c^{+++}$plot $c$ is representative of the hydrated samples with the exception of the exact localization of $\mathbf{T}_{\mathbf{g}}$. 


\section{Thermogravimetry (TG)}

TG was conducted with a Mettler Toledo STGA 851e thermogravimetric system (Mettler Toledo, Switzerland). $500 \mathrm{mg}$ of the air-dried sample were placed into a ceramics crucible, with an $\mathrm{Al}_{2} \mathrm{O}_{2}$ filled crucible used as a reference. Thermogravimetric analysis was conducted under dry air at a flow rate of $200 \mathrm{~mL} \mathrm{~min}^{-1}$. The sample was heated at $5 \mathrm{~K} \mathrm{~min}^{-1}$ to $120^{\circ}$ and then tempered isothermally for $30 \mathrm{~min}$ to remove physisorbed water. After $30 \mathrm{~min}$, no further significant weight losses were detected. In the next step, the sample was cooled to $25^{\circ} \mathrm{C}$ and subsequently re-heated with $5 \mathrm{~K} \mathrm{~min}^{-1}$ to $600^{\circ} \mathrm{C}$. The sample weight and the differential thermal analysis (DTA) signal was recorded as a function of temperature. The DTA signal and the first derivative of the sample weight, expressed by the differential thermogravimetry (DTG) signal, are plotted as a function of temperature.

\section{Results}

$D S C$

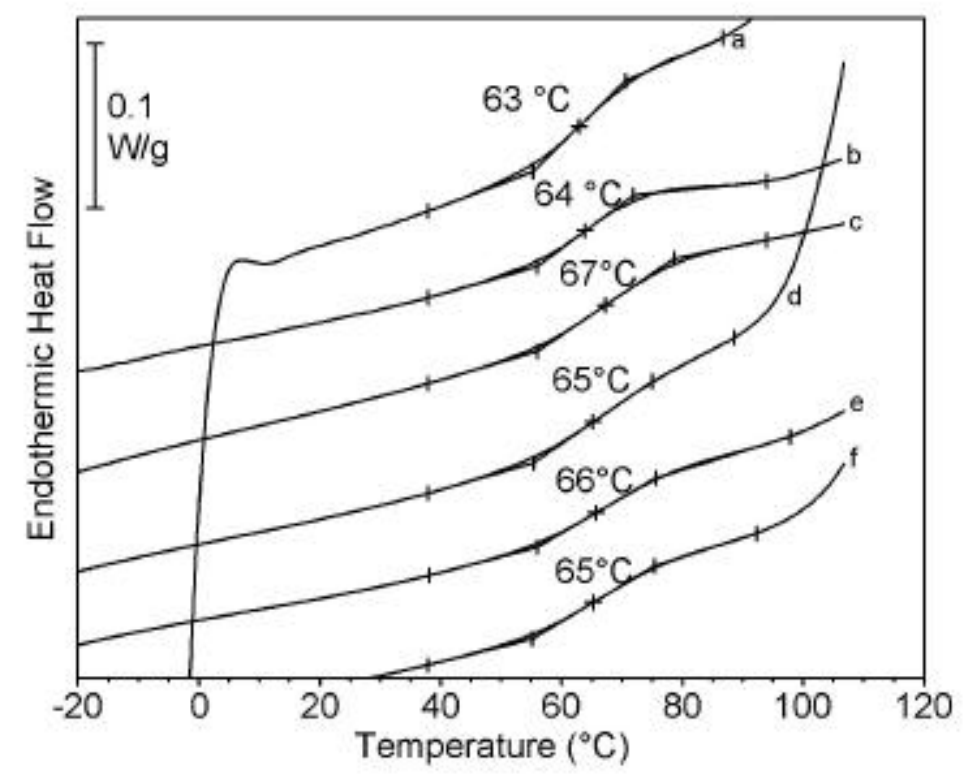

Fig. SI-2. Representative DSC thermograms of the air dried peat sample, recorded with slightly differing temperature ranges. The investigated temperature range was $0-100^{\circ} \mathrm{C}$ for plot a, -40 to $110^{\circ} \mathrm{C}$ for plot $\mathrm{b}$, and -50 to $110^{\circ} \mathrm{C}$ for plots $\mathrm{c}$ through $\mathrm{f}$. 


\section{Thermogravimetry}

Fig. SI-3 shows the DSC, DTG and DTA trace of the peat sample following removal of the physisorbed water. The DTG trace reveals classical behavior suggesting an endothermic weight loss $(2 \%)$ from 120 to $200{ }^{\circ} \mathrm{C}$ associated with bound water, and two exothermic weight losses (20\% between $200{ }^{\circ} \mathrm{C}$ and $320{ }^{\circ} \mathrm{C}$, and $36 \%$ between $320^{\circ} \mathrm{C}$ and $600{ }^{\circ} \mathrm{C}$ ) likely associated with organic matter decomposition.

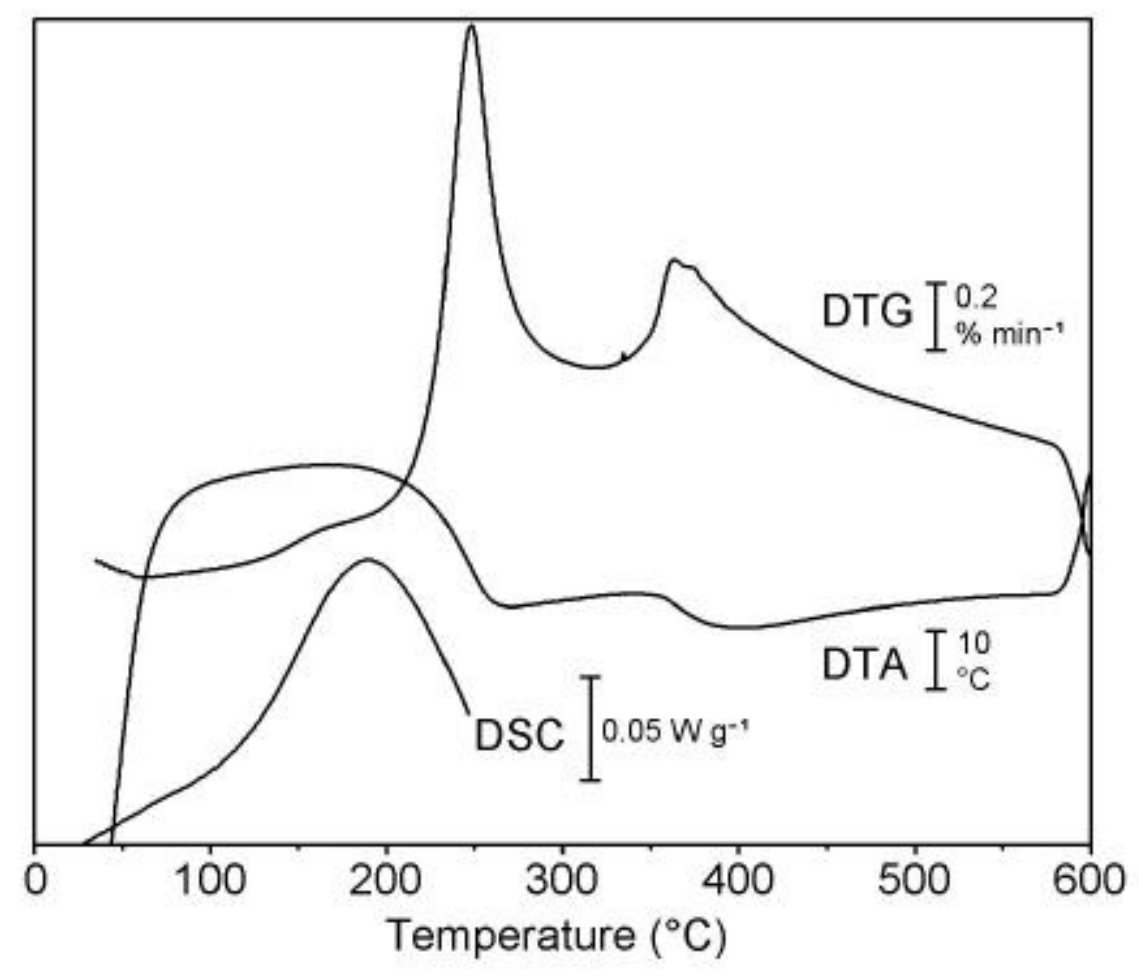

Fig. SI-3. Weight loss (DTG) and DTA trace of thermogravimetry of the air-dried sample under oxidizing conditions after water removal and corresponding DSC thermogram recorded up to $250^{\circ} \mathrm{C}$ in an open pan. 


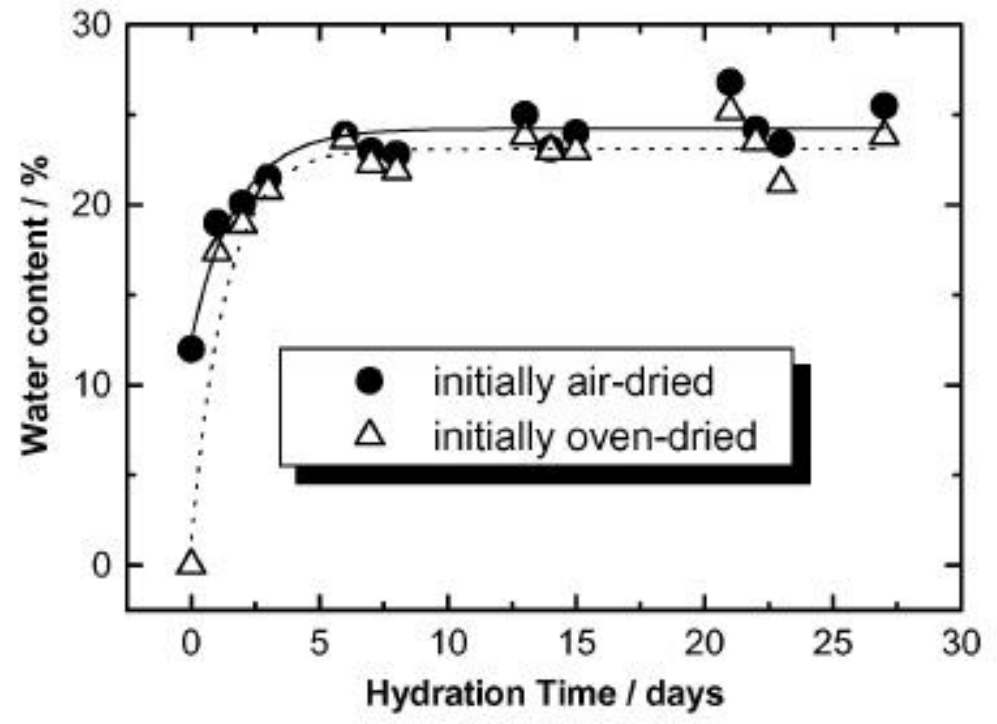

Fig. SI-4. Water uptake from the atmosphere: water content as a function of hydration time.

Table SI-1. List of abbreviations

\begin{tabular}{|l|l|}
\hline DSC & Differential scanning calorimetry \\
\hline NOM & Natural organic matter \\
\hline OM & Organic matter \\
\hline RH & Relative humidity [\%] \\
\hline SOM & Soil organic matter \\
\hline TMA & Thermomechanical Analysis \\
\hline$C_{W}$ & Water content of the hydrated polymer (wet mass basis) \\
\hline$\Delta C_{p}$ & change of heat capacity $\left[\mathrm{J} \mathrm{g}^{-1} \mathrm{~K}^{-1}\right]$ \\
\hline$t$ & Hydration time [days] \\
\hline$T_{g}$ & $\begin{array}{l}\text { Glass transition temperature }\left[{ }^{\circ} \mathrm{C}\right] \\
\text { Glass transition temperature at infinite hydration time and at } t=0, \text { respectively }\end{array}$ \\
\hline$\Theta$ & $\begin{array}{l}\text { Water content (dry mass basis) } \\
\text { Water content at infinite hydration time and at } t=0, \text { respectively }\end{array}$ \\
\hline$\tau_{W}, \tau_{T}, \Theta^{\infty}, \Theta^{o}$ & $\begin{array}{l}\text { Time constants (i.e. reciprocal rate constants) of water uptake and development } \\
\text { of } T_{g}, \text { respectively [days] }\end{array}$ \\
\hline
\end{tabular}

